\title{
Does Being Green Mediate the Effect of Organizational Characteristics on Performance in High Performing Firms?
}

\author{
Peter Wanjohi ${ }^{1}$, Hazel Gachoka ${ }^{2}$, John Kihoro ${ }^{3}$, Martin Ogutu ${ }^{4}$ \\ ${ }^{1}$ Entrepreneurship and Procurement Department, Jomo Kenyatta University of Agriculture and Technology, \\ Kenya \\ ${ }^{2}$ Entrepreneurship and Procurement Department, Jomo Kenyatta University of Agriculture and Technology, \\ Kenya \\ ${ }^{3}$ Department of Statistics, Cooperative University College, Kenya \\ ${ }^{4}$ Department of Business Management, University of Nairobi, Kenya
}

\begin{abstract}
A major objective of business organizations is to out-compete their rivals at the market place and dominate it. To achieve this, a miried of strategies are applied. Most involve scanning the environment to take advantage of the changes in tastes and prefences among the customers and instituting measures to serve these tastes. In the past decade and in to the mid and long term future, proactive environmental management is becoming a major strategic issue. This is a fact firms have to deal with. Environmental conciousness is being pussed by legal pressure, customer pressure and decreasing natural resources. A major question that organizations have to contend with is wether being green is more benegitial than its costs to the firms. Due to the costs inccured in 'being green', and the often indirect nature of benefits acrued, many firms tend to lay emphasis to organizational characterists for high performance. These are innovativeness, customer orientation, quality emphasis and management. This paper will review available literature in trying to bring out the relationship between adoptions of green to the above organizational characteristics of high performing firms as a pointer that being green can be incorporated in the organizational characteristics and boost performance.

Keyword: Environment, organizational characteristics, high performing organizations, strategy,
\end{abstract}

\section{Introduction}

It is widely accepted that human economic activity is affecting the natural environment leading to global warming and its attendant challenges. Galdeano-Go'mezet al. $(2008)^{[1]}$, observed that this acceptance has led to greater political and social demands on firms to reduce their environmental impact. As a result, firms today are under legal obligation to act in certain ways to preverve and concerve the environment. In Kenya, the Environment Management and Coordination Act of 1999 is an example of such legal regimes. In addition, sorounding communities, staff and customers all have demands on the firm to take care of the environment, which demands go beyound the legal requirements.

These observations have lead Henri and Journeault (2008) ${ }^{[2]}$, to conclude that the ability of organizations to manage their environmental performance is emerging as a strategic issue for firms. As such more emphasis needs to be placed on it. So far, authorities in this area have not come to a concensus on wether adopting green environment has more benefits than costs or the vice vasa. While some argue that environmental management leads to competitive advantage benefits to the firm (Gore, 1992 $2^{[3]}$; Porter and Van der Linde, $1995^{[4]}$; Trung and Kumar, $2005^{[5]}$ ), others oppose this argument (Jaffe et al., 1995 ${ }^{[6]}$; Walley and Whitehead, $\left.1994^{[7]}\right)$. Walley and Whitehead $(1994)^{[7]}$, say that the idea that environmental initiatives will systematically increase profits is an appealing proposition. In their view however, this idea is unrealistic. They conclude that environmental efforts are not cheap.

After studying the arguments by several scholars, Lo'pez-Gamero, M.D., et al.(2009) ${ }^{[8]}$, concludes that there is no single, direct relationship between proactive environmental management and a firm's performance. In their view, and quoting Claver et al. (2007) ${ }^{[9]}$, this relationship seems to depend on environmental management and environmental performance, the firm resources most directly associated with their proactive environmental management, and the effect that proactive environmental management and environmental performance have on competitive advantage and financial performance. This paper will be grounded on this belief. Perfomance will therefore be a factor of how the envirmnental management measures taken rhyme with the organizations's own processes and resources to give a superior product or service.

For the rhyming to occur, the environmental management measures taken must be capable of being encompased into the organizational characteristics. In high performing organizations, these characteristics are responsible for a firm's superior performance compared to others in the same industry (Owen et al., 2001 ${ }^{[10]}$; Wiley, $\left.2010^{[11]}\right)$. This paper will strive to bring out how environmental management measures can be incorporated in to the organizational characteristics of a firm to result in better performance. 
This paper has the folling flow. To begin with, we shall review relevant literature. Next, we shall link environmental management measures to organizational characteristics and explore how the adoption of green environment inpacts on the same in relation to its effect on a firm's performance. There after there will be a sumary and a conclution.

The Concept of a Green Business and organizational characteristics of high performing organizations

Unregulated human economic activity often leads to environmental degradation. Green business involve application of production processes which use inputs with relatively low environmental impacts, which are highly efficient and which generate little or no pollution. Green business encompasses source reduction (waste or pollution minimization or prevention), recycling and green product design (Porter and Linde, 1995) ${ }^{[4]}$. Source reduction includes actions aimed at reducing waste initially generated. Recycling includes using or reusing wastes as ingredients in a process or as an effective substitute to a commercial product, or returning the waste to the original process which generated it as a substitute for raw material feedstock. Green product design involves creating products whose design, composition and usage minimizes negative environmental impacts through out the products life cycle (Florida and Atlas, 1997) ${ }^{[12]}$.

Several factors are known to impact a firm's performance compared to others in the same industry. Research on high performing organizations (HPOs) indicates that they consistently deliver high quality products and services (Owen et al., 2001) ${ }^{[10]}$. HPOs can be differentiated by their continually superior performance such as higher customer satisfaction, greater customer loyalty and higher productivity (Wiley, 2010) ${ }^{[11]}$. A keen review of literature suggests that HPOs share the following four fundamental characteristics: customer orientation, quality emphasis, innovation and effective leadership.

\section{Theoretical Review}

Several theories have been advanced to explain organizational performance. In this study, five theories will be analysed. These are the stakeholder theory, natural resource based view theory, the innovation theory, the theories on adoption of green environment which are the economic approach theory and the institutional sociology theory.

\section{Stakeholder theory}

According to Freeman (1984b) ${ }^{[13]}$, a stakeholder is any group or individual who can affect or is affected by the achievement of the organization's objectives. Friendman and Miles $(2006)^{[14]}$, states that the organization itself should be thought of as grouping of stakeholders and the purpose of the organization should be to manage their interests, needs and viewpoints. Freeman $(1984 a){ }^{[15]}$, defines stakeholders as those groups who are vital to the survival and success of the corporation.

The theory is in part concerned with the influence of a wide range of actors in an organization's environment on organizational performance as many researchers have argued (Preston, $1995^{[16]}$; Freeman $1984 b^{[13]}$; Quinn and Jones, 1995 ${ }^{[17]}$; Mitchell et al., 1997 $7^{[18]}$ ). Unlike traditional input-output models of organization performance, stakeholder theory emphasizes the interaction between interest groups such as the organization's employees, members of the social community, shareholders, and other allied organizations, in determining organization performance.

Some stakeholders identified by Friendman and Miles (2006) ${ }^{[14]}$, include:Customers, Employees, Local communities, Suppliers and distributors, The media, The public in general, Business partners, Future generations, Past generations (founders of organizations), Academics, Competitors, Non Governmental Organizations or activists - considered individually, Stakeholder representatives such as trade unions or trade associations of suppliers or distributors, Financiers, other than stockholders (dept holders, bondholders, creditors), Competitors, Government, regulators and policymakers. Modern writers have identified the natural environment as part of an organization's stakeholders. This has been informed by the important role that the natural environment plays in the success of businesses.

Most raw materials are found as naturally occurring substances, plants and plant products, animal or animal derivatives and minerals among others. The environment also acts as the sink at the end of the pipe. It is thus impossible to think of success and performance of manufacturing firms without the natural environment. According to Michael (1980) ${ }^{[19]}$, competitive advantage and hence high performance can be achieved by controlling raw material source. In order to safeguard this important stakeholder, firms have an important role in pollution and emission control through active and proactive measures.

\section{Natural resource based view theory}

Researchers in the field of strategic management have long understood that competitive advantage depends on the match between distinctive internal (organizational) capabilities and changing external (environmental) circumstances (Andrews, 1971 ${ }^{[20]}$; Chandler, 1962 ${ }^{[21]}$; Hofer et al., $1978^{[22]}$; BlackwellLondon, 
$\left.1959^{[23]}\right)$. However, it has only been during the past decade that a bonafide theory, known as the resource-based view of the firm, has emerged, articulating the relationships among firm resources, capabilities, and competitive advantage.

\section{Theory of innovation}

Schumpeter (1943) ${ }^{[24]}$, attributes profit to dynamic changes resulting from an innovation.To start with he takes a capitalist closed economy which is in a stationary equilibrium. This equilibrium is characterized by what Schumpeter calls a "circular flow" which continues to repeat itself for ever. In such a static state, there is perfectly competitive equilibrium. The price of each product just equals its cost of production and there is no profit. Only exogenous factors like whether conditions can cause changes in the circular flow position. In the circular flow position goods are being produced at a constant rate. This routine work is being performed by the salaried managers. It is the entrepreneur who disturbs the channels of this circular flow by the introduction of an innovation.

Schumpeter assigns the role of an innovator not to the capitalist but to the entrepreneur. He emphasizes creating new value-generating activities as a means of searching for higher profits from innovation. Such value generation can be tapped from adoption of the green environment. Firms can use the green environment creatively to gain a competitive advantage. Proto and Supino (1999) ${ }^{[25]}$, argued that the quality of the environmental information the enterprise reports about its activities might be its biggest source of competitive advantage when seeking to gain customer loyalty. Furthermore, Claver et al. (2004) ${ }^{[9]}$, state that cost savings from the reduced use of raw materials and energy and the improvement of productive processes can become competitive advantages for enterprises as well.

\section{Theories on adoption of green environment}

Two theories provide insights on why firms adopt environmental management practices. The economic approach describes firms' adoption behavior as driven by performance outcomes. This line of research seeks to identify the circumstances when it pays to be "green" and that managers exhibit rational behavior when they adopt "beyond compliance" practices (Russo and Fouts, 1997 ${ }^{[26]}$; Andrew and Lenox, 2001 ${ }^{[27]}$ ). The second adoption theory is rooted in institutional sociology proposes through which firms respond to institutional pressures. The institutional sociology framework emphasizes the importance of regulatory, normative and cognitive factors that affect firms' decisions to adopt a specific organization practice, above and beyond the technical efficiency of the practice. Institutional theory places particular emphasis on legitimation processes and the tendency for institutionalized organizational structures and procedures to be taken for granted, regardless of their efficiency implications (Hoffman and Ventresca,2002) ${ }^{[28]}$.

\section{The moderating effect of adopting green on organizational Characteristics}

The figure below shows the authors' conceptualization of the relationship between the dependent and independent variables.

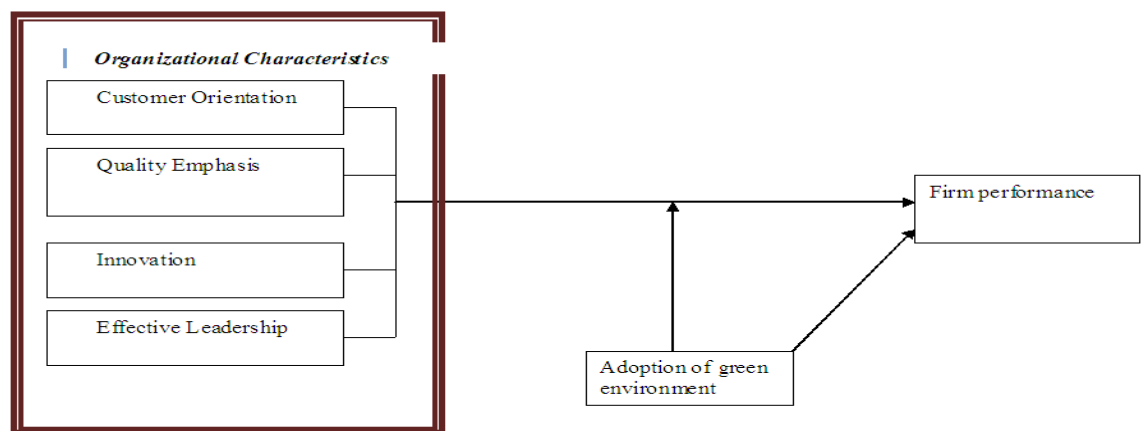

Fig. 1: Diagram showing the relationship between adoption of green in to organizational characteristics and the effect on performance. (Source, Authors)

On customer Orientation Slater and Narver (1994) ${ }^{[29]}$, say that customer orientation is an organization's disposition to continuously deliver superior value to its customers. Empirical evidence supports the link between 
customer orientation and business performance. According to Narver et al. (2000) ${ }^{[30]}$, organizations are more successful when they embrace a customer-focused orientation. In addition, Appiah-Adu and Singh (1998) ${ }^{[31]}$, and Hartnell et al. (2011) ${ }^{[32]}$, found that customer orientation is positively related to operational performance such as quality of goods and service, new products' success, sales growth and return on investment.

According to Doug Miller, chair of GlobeScan Inc., their research showed that customers are not acting like they did in other economic downturns. Rather than softening their activism, consumers are more demanding than ever before, that companies maximize their societal and ecological contributions. This has led HP in its Global Citizenship Report (2008) ${ }^{[33]}$, to quip that "it seems clear that only the best corporate citizens will thrive in tomorrow's marketplace". Firms that show concern for the environment earns them integrity and socially responsible reputation. Such a reputation can build customer loyalty based on distinct values differentiating the brand from the competition. This is more prominent in the developed countries. More than two-thirds (68\%) of Canadians take a company's CSR performance into consideration when they make everyday purchases (Scotiabank 2007) ${ }^{[34]}$.

Due to globerlization of the world economy, such sentiments are now permiating the developing countries. A study conducted by Olalekan $(2010)^{[35]}$, in Nigeria indicated that there was a positive and significant relationship between customer orientation and firm performance in the context of Nigerian small and medium scale business. The result also revealed that marketing information system and managerial attitude moderated the relationship. $70-80 \%$ of public companies' valuation in American and Western stock markets depends on expectations of the company's cash flow beyond the next three years.

Companies' reputations strongly shape those expectations and corporate citizenship is the top driver of reputation, according to the Reputations Institute's 2007 global survey as reported by Fall $(2008)^{[36]}$. Within a global context, Canada is the third most demanding market after Australia and Great Britain for corporate values to extend beyond financial gain and are the most likely to punish those companies they consider to be socially irresponsible. In Canada, $34 \%$ of respondent agree to the statement "I would be more likely to purchase products or services from a company with a good reputation for environmental responsibility"; $42 \%$ in US. (Tandberg, Global retail consumers segmented by willingness to pay for products with environmental and social benefits, 2007).

Quality Emphasis is defined by Powell (1995) ${ }^{[37]}$, as a set of organizational practices put in place to ensure the consistent production of high quality products and services. Empirical research by Milan et al. (2012) ${ }^{[38]}$; Juran (1993) $)^{[39]}$, and Powell $(1995)^{[37]}$, has established the link between quality emphasis and organizational performance. Opportunity to develop cutting edge technology and innovative products and services for unmet social or environmental needs that could translate to business uses, patents, proprietary knowledge.

On the Firm's Management, Hansen andWernerfelt (1989) ${ }^{[40]}$, argued that a firm's performance is a factor of the quality or quantity of its resources which includes management. Work by organizational researchers including Cameron (1986) ${ }^{[41]}$, and Steers $(1975)^{[42]}$, suggests that managers can influence the behavior of their employees (and thus the performance of the organization) by taking into account factors such as the formal and informal structure, the planning, reward, control and information systems, their skills and personalities, and the relation of these to the environment. That is, managers influence organizational outcomes by establishing context, and that context is the result of a complex set of psychological, sociological, and physical interactions.

Authorities in this area such as Wiley (2010) ${ }^{[11]}$, say that an organization's success is fundamentally dependent upon the skills and actions of its leaders. This is especially in highly competitive markets where organizations face the challenges of scarce opportunities and limited resources (Wasserman et al., 2001) ${ }^{[43]}$. Further, Researchers argue that the quality of executive leaders explains around $45 \%$ of an organization's performance (Day and Lord, 1988) ${ }^{[44]}$, and effective leadership positively affects organizational performance outcomes such as labor productivity, return on assets, and outputs of patents (Wang et al., 2011) ${ }^{[45]}$.

\section{Conclusion}

From the above, it is possible to conceptualize that green can be applied as part of any of the four organization characteristics for high performance. Such an adoption of green would enhance the effect of the organizational characteristics on performance. In our view, this is a promising proposition to businesses which are working very hard trying to get solutions that will give them an edge in the increasingly competitive market. The Authors recommend a further empirical study to develop a model that can act as a guide to businesses on the exact moderating effect of adoption of green on the oeganizational characteristics and the impact of that to a firm's performance. 


\section{Reference}

[1]. Andrews, K. R. (1971). The Concept of Corporate Strategy. Richard D. Irwin, Homewood.

[2]. Andrew, A. K. and Lenox, M. J. (2001). Does it really pay to be green. Journal of idustrialcology.

[3]. Appiah-Adu, K. and Singh, S. (1998). Customer orientation and performance: A study of smes. Management Decision, 36:385-394.

[4]. BlackwellLondonr (1959). The Theory of Growth of Firm. Oxford University Press, 3rd edition.

[5]. Chandler, A. (1962). Strategy and Structure. The MIT Press.

[6]. Claver, E., Lo' pez, M.D., Molina, J.F., Tar1', J.J., (2007). Environmental management and firm performance: a case study. Journal of Environmental Management 84, 606-619.

[7]. Cameron, T. A. (1986). Some reflections on comparable worth. Contemporary economic Policy, 4(2):33- 39.

[8]. Day, D. V. and Lord, R. G. (1988). Executive leadership and organizational performance: suggestions for a new theory and methodology. Journal of Management, 14:453-464.

[9]. Florida, R. and Atlas, M. (1997). Report of field research on enviromenatally-concious manufacturing in the United States. Technical report, Carnege Mellon University.

[10]. Freeman, R. E. (1984a). Strategic management: A stakeholder approach. Boston, Pitman.

[11]. Freeman, R. E. (1984b). Strategic management: A Stakeholder Approach. Cambridge University Press

[12]. Friendman, A. and Miles, S. (2006). Stakeholders: Theory and Practice. Oxford University Press USA.

[13]. Galdeano-Go' mez, E., and Ce' spedes-Lorente, J., and Martı'nez-del-R1'o, J. (2008). Environmental performance and spillover effects on productivity: evidence from horticultural firms. Journal of Environmental Management 88, 1552-1561. ${ }^{[1]}$

[14]. Gore, A. (1992). Earth in the Balance. Houghton-Mufflin. Boston

[15]. Hansen, G. S. and Wernerfelt, B. (1989). Derterminations of firm performance: The relative importance of economic and organizational factors. Strategic Management Journal, 10 (5):399 - 411.

[16]. Hartnell, C. A., Ou, A. Y., and Kinicki, A. (2011). Organizational culture and organizational effectiveness: A meta- analytic investigation of the competing values framework's theoretical suppositions. Journal of Applied Psychology, 96:677-694.

[17]. Henri, J.-F. and Journeault, M. (2008). Environmental performance indicators: an empirical study of Canadian manufacturing firms. Journal of Environmental Management 87, 165-176.

[18]. Hofer, W., C., Schendel, and Dan (1978). Strategy formulation: Analytical concepts. West Publing Company. St. Paul.

[19]. Hoffman, A. J. and Ventresca, M. J. (2002). Organization, Policy and the Natural Environment: Institutional and Strategic Perspectives. Standford University Press.

[20]. Jaffe, A., Peterson, S., Portney, P., Stavins, R. (1995). Environmental regulation and the competitiveness of U.S. manufacturing: what does the evidence tell us? Journal of Economic Literature 33, 132-163.

[21]. Juran, J. (1993). Made in U.S.A.: A renaissance in quality. Harvard Business Review, pages 42-50.

[22]. Lo' pez-Gamero, M.D., Claver-Corte' s, E., Molina-Azorı'n, J.F., (2008). Complementary resources and capabilities for an ethical and environmental management: a qual/quan study. Journal of Business Ethics 82, 701-732.

[23]. Michael, P. E. (1980). Competitive strategy. New York Free Press.

[24]. Milan, S., Petr, S., Jiri, S., and S., P. (2012). Relationship between quality and performance: Tourism companies in the Czech Republic. Review of Economic Perspectives, 11:195-222.

[25]. Mitchell, R. K., Agle, B. R., and Wood, D. J. (1997). Toward a theory of stakeholder identification and salience: Defining the principle of who and what really counts. Academy of Management Review.

[26]. Narver, J. C., Slater, S., and MacLachlan, D. L. (2000). Total market orientation on business profitability. Journal of Marketing, 54:20-35.

[27]. Olalekan, A. (2010). Customer orientation and firm performance among nigerian small and medium scale businesses. International Journal of Marketing Studies, 2:197-212.

[28]. Owen, K., Mundy, R., Guild, W., and Guild, R. (2001). Creating and sustaining the high performance organization. Managing Service Quality, 11:10-21.

[29]. Porter, M., Van der Linde, C., (1995), Toward a new conception of the environment competitiveness relationship. Journal of Economic Perspectives 9, 97-118.

[30]. Powell, T. (1995). Total quality management as competitive advantage: A review and empirical study. Strategic Management Journal, 16:15-37.

[31]. Preston, T. D. L. E. (1995). The Stakeholder theory of the corporation, volume 20 (1). The Academy of Management Review.

[32]. Proto, M. and Supino, S. (1999). The quality of environmental information: A new tool in achieving customer loyalty. Total Quality Management.

[33]. Quinn, D. P. and Jones, T. M. (1995). An agent morality view of business policy. Academy of Management Review, 20,(January):22-42.

[34]. Russo, M., and Fouts, P. A. (1997). A resource based perspective on corporate environmental performance and profitability. Academy Management Review.

[35]. Schumpeter, J. (1943). Capitalism, Socialism and Democracy. Allen and Unwin: London.Strandberg (2009). The business case for sustainability produced.http://www.corostrandberg.com/pdfs/Business-Case-for-Sustainability-21.pdf.

[36]. Steers, R. M. (1975). Problems in measurement of organizational effectiveness. Sage Publications.

[37]. Trung, D., Kumar, S., (2005), Resource use and waste management in Vietnam hotel industry. Journal of Cleaner Production 13, 109-116.

[38]. Walley, N., Whitehead, B., (1994), It's not easy being green. Harvard Business Review 72, 46-52.

[39]. Wang, G., Oh, I., Courtright, S. H., and Colbert, A. E. (2011). Transformational leadership and performance across criteria and levels: A meta-analytic review of 25 years of research. Group Organization Management, 36:223-270.

[40]. Wiley, J. W. (2010). Driving success through performance excellence and employee engagement. Kenexa High Performance Institute.

[41]. Wasserman, N., Nohria, N., and Anand, B. (2001). When does leadership matter? The contingent opportunities view of CEO leadership. Technical report, Harvard University, 